\title{
Undertaking the surgical count: An observational study
}

Follow this and additional works at: https://www.journal.acorn.org.au/jpn

Part of the Health Services Administration Commons, Health Services Research Commons, Perioperative, Operating Room and Surgical Nursing Commons, and the Surgery Commons

(c) (7)

This work is licensed under a Creative Commons Attribution 4.0 License.

\section{Recommended Citation}

Warwick, Victoria Ruth Dr; Gillespie, Brigid M. Professor; McMurray, Anne Professor; and Clark-Burg, Karen G. Professor (2021) "Undertaking the surgical count: An observational study," Journal of Perioperative Nursing: Vol. 34 : Iss. 3 , Article 1.

Available at: https://doi.org/10.26550/2209-1092.1089

https://www.journal.acorn.org.au/jpn/vol34/iss3/1

This Article is brought to you for free and open access by Journal of Perioperative Nursing. It has been accepted for inclusion in Journal of Perioperative Nursing by an authorized editor of Journal of Perioperative Nursing. 


\section{Authors}

Dr Victoria Ruth Warwick

DrN, RN

Perioperative Nurse Unit Manager, Fiona Stanley Hospital and Fremantle Hospital Group, Perth, Western Australia

Professor Brigid M Gillespie

PhD, RN, FACORN

Professor of Patient Safety, School of

Nursing and Midwifery, Griffith University

and Gold Coast University Hospital, Gold

Coast Health, Nursing and Midwifery

Education and Research Unit

Professor Anne McMurray

AM, PhD, RN, FACN

Emeritus Professor, School of Nursing and

Midwifery

Principle Research Fellow, Integrated

Care Program, Centre for Applied Health

Economics, Menzies Health Institute

Queensland, Griffith University, Gold Coast

Campus

Professor Karen G Clark-Burg

PhD, MBA (Exec), RN

Dean School of Nursing and Midwifery,

The University of Notre Dame Australia

\section{Corresponding author}

Dr Victoria Ruth Warwick

DrN, RN

Perioperative Nurse Unit Manager, Fiona Stanley Hospital and Fremantle Hospital Group, Perth, Western Australia

Vicky.warwick@health.wa.gov.au

\section{Undertaking the surgical count: An observational study}

\section{Abstract \\ Objective}

To systematically measure and describe perioperative nurses' surgical count practices using the Surgical Count Observational Tool, to measure conformity with standardised processes and identify barriers and enablers influencing nurses' practices.

\section{Sample and setting}

A large public tertiary hospital in Western Australia.

\section{Methods}

The Surgical Count Observational Tool (SCOT) was developed using the Content Validity Index over two Delphi panel rounds and then pilot tested. Individual observations were analysed according to 14 criteria based on the 2016 Australian College of Perioperative Nurses (ACORN) standard 'Management of accountable items used during surgery and procedures". Count processes were observed over two consecutive weeks across six specialist perioperative teams including nurses, surgeons, anaesthetists and technicians to measure compliance with the ACORN standard. The SCOT and a field diary were then used in an observational study of 83 nursing staff, including 54 circulating nurses and 29 instrument nurses, over a period of 57 hours. Interrater reliability was calculated using Cohen's kappa. Descriptive statistics were used to analyse observational data.

\section{Results}

Of the 1268 count practices observed, 759 were compliant with the ACORN standard, representing a 60 per cent compliance rate.

\section{Conclusion}

Consistency and compliance rates were lower than expected. Patient, case, environmental factors and expectations of surgeons and co-workers were observed to act as barriers to best practice in perioperative nurses undertaking a surgical count, while nurse's knowledge was observed to act as an enabler.

Keywords: surgical count, perioperative, structured observations, best practice, patient safety, standard 
Table 1: Components of observational tool (based on the 2016 ACORN accountable items standard')

\begin{tabular}{|c|c|c|c|}
\hline $\begin{array}{c}\text { Component } \\
\text { number }\end{array}$ & Component & Descriptor & $\begin{array}{l}\text { Number of } \\
\text { behavioural } \\
\text { indicators }\end{array}$ \\
\hline 1 & Count process & The recommended steps or actions required to undertake a count. & 25 \\
\hline 2 & No count required & $\begin{array}{l}\text { No accountable items used during procedure as the procedure } \\
\text { does not involve opening a body cavity or making an incision. }\end{array}$ & 2 \\
\hline 3 & $\begin{array}{l}\text { Accountable items } \\
\text { removed from OR }\end{array}$ & $\begin{array}{l}\text { Items that are part of the count process remain in the OR for the } \\
\text { duration of the procedure. }\end{array}$ & 5 \\
\hline 4 & $\begin{array}{l}\text { Absorbable gauze } \\
\text { swabs, wool balls, } \\
\text { pharyngeal packs } \\
\text { utilised }\end{array}$ & $\begin{array}{l}\text { Accountable items that may not have an x-ray identifiable strip } \\
\text { but are used intra-operatively. These items are sometimes divided } \\
\text { and must be recorded on the count sheet. }\end{array}$ & 13 \\
\hline 5 & $\begin{array}{l}\text { Incorrect number of } \\
\text { items in package }\end{array}$ & $\begin{array}{l}\text { Accountable items come in a standardised number (for example, } \\
1,5 \text { and } 10 \text { ). When opening a package the right number of items } \\
\text { should be as stated on the package. }\end{array}$ & 7 \\
\hline 6 & Count relief & $\begin{array}{l}\text { A relieving nurse that undertakes a component of the count when } \\
\text { the original staff member is not available, for example, during a } \\
\text { tea break. }\end{array}$ & 9 \\
\hline 7 & $\begin{array}{l}\text { Simultaneous } \\
\text { procedures }\end{array}$ & $\begin{array}{l}\text { Two different procedures on the same patient that occur at } \\
\text { the same time. May be the same surgical team or two different } \\
\text { surgical teams. }\end{array}$ & 5 \\
\hline 8 & $\begin{array}{l}\text { Sequential } \\
\text { procedure. OR } \\
\text { cleared/not cleared } \\
\text { between procedures }\end{array}$ & $\begin{array}{l}\text { Different procedures that occur on the same patient but at } \\
\text { different times. Same original sterile set up may or may not be } \\
\text { used. }\end{array}$ & 14 \\
\hline 9 & $\begin{array}{l}\text { Intentionally } \\
\text { retained items }\end{array}$ & $\begin{array}{l}\text { Accountable items are left in or on the patient at the end of a } \\
\text { procedure, for example, packing of a cavity to be removed later. }\end{array}$ & 7 \\
\hline 10 & $\begin{array}{l}\text { Removal of } \\
\text { intentionally } \\
\text { retained items }\end{array}$ & $\begin{array}{l}\text { When a patient returns to OR to have accountable items removed } \\
\text { that were left in situ by necessity and were documented on the } \\
\text { original count sheet as being retained. }\end{array}$ & 2 \\
\hline 11 & Tray lists & $\begin{array}{l}\text { Paper lists of instruments that accompany individual surgical } \\
\text { trays. }\end{array}$ & 15 \\
\hline 12 & $\begin{array}{l}\text { Progressive counting } \\
\text { away technique }\end{array}$ & $\begin{array}{l}\text { The process followed to account for all accountable items, for } \\
\text { example, handing off packs from the sterile field and placing in a } \\
\text { container in groups of five. }\end{array}$ & 9 \\
\hline 13 & Emergency situation & $\begin{array}{l}\text { The patient enters the OR and there is no time to undertake a } \\
\text { surgical count due to a medical or surgical emergency. }\end{array}$ & 3 \\
\hline 14 & Incorrect count & $\begin{array}{l}\text { The original count tally for the procedure is not congruent with } \\
\text { the final count tally on completion of the procedure. }\end{array}$ & 8 \\
\hline \multicolumn{3}{|c|}{$\begin{array}{ll}\text { Total number of items }\end{array}$} & 124 \\
\hline
\end{tabular}




\section{Background}

In 2006, the Australian Commission on Safety and Quality in Health Care (ACSQHC) was established as part of an Australian initiative to improve safety and quality in health care. The ACSQHC is jointly funded by each Australian state and territory and one of its roles is to advise on best practice and provide recommendations for nationally agreed safety and quality standards. In 2002, health ministers endorsed a table of eight descriptors of sentinel events that became reportable to the ACSQHC. These were related to harm, serious harm or death that a patient sustained while under the care of a health care facility $(\mathrm{HCF})^{2}$. One of these sentinel events was retained items in surgery.

In Western Australia during 2015 and 2016, there were 434 reportable events within HCFs, three of which were related to retained items in surgery ${ }^{3}$. The surveillance unit identified contributing factors as communication, the environment and practitioner knowledge, skill and competence. Failure to follow latest policy, procedure or guidelines was seen as an important contributing factor, an issue that has also been identified in the USA. The American Joint Commission Sentinel Event Alert 4 published a 10-15 per cent error rate in surgical count practices, which was attributed to failure to follow policy and procedure. This is a significant issue, as it can increase the likelihood of an unintentionally retained item (URI).

Rowlands and Steeves ${ }^{5}$ review of studies on incorrect surgical processes found a significant risk of URIs in surgery due to failure to follow current surgical count process and procedure. Their review included studies of possible causes of URIS in surgery but failed to identify current barriers to and enablers of perioperative nurses following best practice when undertaking a surgical count.

The surgical count is a structured, standardised process developed by the Australian College of Perioperative Nurses (ACORN) to assist nurses in maintaining best practice standards and ensuring patients receive safe, high quality nursing care ${ }^{6}$. Despite endorsement by peak national and international perioperative bodies, variations in clinical practice continue to occur. This study aimed to systematically examine perioperative nurses' surgical count practices in one major Australian hospital.

\section{Objective}

The aim of this prospective observational study was to describe current surgical count practices of perioperative teams and calculate overall compliance with the relevant ACORN practice standard using a specially developed observational tool - the Surgical Count Observational Tool (SCOT). This tool was developed using behavioural performance markers that reflected the count process as recommended in the 2016 version of the ACORN standard 'Management of accountable items used during surgery and procedures' (the ACORN accountable items standard). Subsumed under the overarching aim were the following two objectives:

1. to develop a tool based on the ACORN accountable items standard

\section{Table 2: Feedback from Delphi participants}

\begin{tabular}{|l|l|l|}
\hline Round 1 feedback & Round 2 feedback & Descriptors \\
\hline $\begin{array}{l}\text { Lack of clarity } \\
\text { sites }\end{array}$ & Add a word to increase clarity & Unclear sentence structure \\
\hline Irrelevant item & $\begin{array}{l}\text { Particular item may not be the same at any given } \\
\text { site, for example, surgeon signing the count sheet }\end{array}$ \\
\hline $\begin{array}{l}\text { Definition of some words } \\
\text { unclear }\end{array}$ & $\begin{array}{l}\text { The relevance of the item listed was unclear } \\
\text { Repetition of items } \\
\text { is very similar to another item }\end{array}$ & $\begin{array}{l}\text { Lomewh of understanding about what was being asked } \\
\text { what is being asked }\end{array}$ \\
\hline Did not respond to item & $\begin{array}{l}\text { Giving a mark of } 1 \text { or } 2 \text { but provided no feedback as } \\
\text { to reason why }\end{array}$ \\
\hline
\end{tabular}


2. to systematically observe perioperative nurses' compliance with surgical count practices recommended in the ACORN accountable items standard using the tool.

The study also aimed to identify barriers and enablers influencing nurses' practices.

\section{Literature review}

The literature reviewed for this study provided information about the surgical count process and concluded that the perioperative nurse's ability to undertake a surgical count was influenced by patient factors, case factors, environmental factors including distraction and noise within the operating room, and individual factors including knowledge of policy development. No empirical studies on the barriers and enablers in undertaking a surgical count were found.

\section{Ethics}

Ethics approval was granted through the university and participating hospital's ethics approval processes. Information about the study was given to participants who provided their informed consent. Research integrity was maintained through joint planning and discussions by the research team. Feedback about the data analysis was provided to participants during in-service sessions at the participating hospital prior to writing the final report and this provided opportunities to clarify or modify findings prior to the final report being written.

\section{Methods}

\section{Observational tool development}

The observational tool contained 14 components of the count process (see Table 1), each consisting of

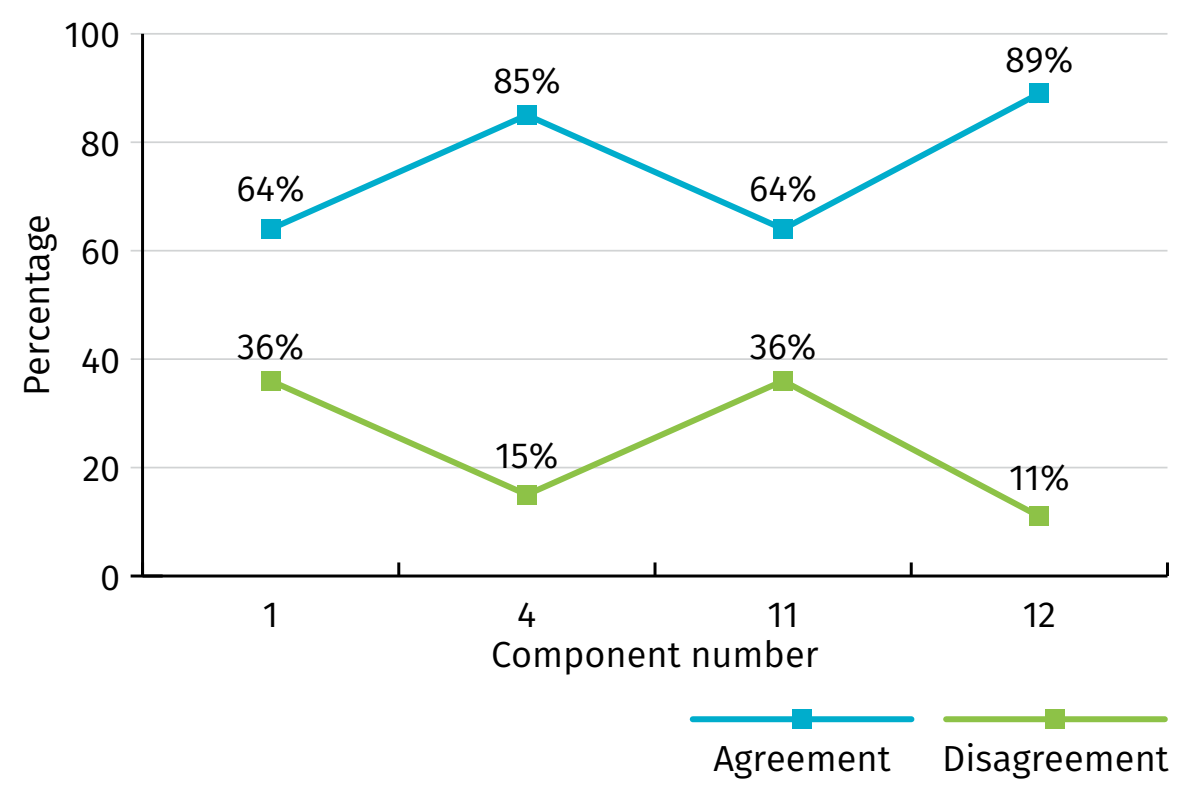

Figure 1: Disagreement between raters following pilot study

behavioural indicators. These were based on the standard 'Management of accountable items used during surgery procedures ${ }^{\prime}$ which outlines the recommended actions that should be taken by the circulating and instrument nurses while undertaking a surgical count.

Each behavioural indicator was formatted with 'Yes', 'No' and 'N/A' (not applicable) tick boxes for ease of recording observed behaviours. In instances where the behaviour was required as part of the count process 'yes' was ticked if the behaviour had been observed and 'no' if it was not observed or undertaken as part of the process. The ' $N / A$ ' tick box was used for any of the behaviours that were not required during the count process. For example, if there were no intentionally retained items for the case observed ' $N / A$ ' was ticked for all the behaviours within that component.

\section{Content validation}

A Delphi study was undertaken to test content validity using the content validity index (CVI)7. Two rounds of the Delphi panel occurred with four out of the ten perioperative nurses who were invited to review the observational tool responding to the request and then providing further feedback on the revised observational tool. All responders had at least 20 years perioperative experience, were aged 36 years or over and held a hospital certificate, diploma or a bachelor's degree in health science

In the first round, responders were requested to review the observational tool by rating each item according to its relevance, with ' 1 ' being not at all relevant through to ' 4 ' being very relevant. Feedback was also encouraged about clarity of wording and flow of items as well as the structure and layout of the document. The level of agreement for the total CVI was 0.75 and 0.66 in rounds one and two respectively, both considered acceptable levels?

Minor edits were made to the observational tool in response to responders' comments (Table 2 ). To maintain the alignment with the ACORN accountable items standard, individual items that may have varied across hospital sites were maintained 
Table 3: Surgical case demographics

\begin{tabular}{|c|c|c|c|c|c|c|}
\hline $\begin{array}{c}\text { Case } \\
\text { number }\end{array}$ & $\begin{array}{l}\text { Patient } \\
\text { ASA }\end{array}$ & Surgical specialty & Operative procedure & $\begin{array}{c}\text { Total } \\
\text { procedure } \\
\text { time } \\
\text { (minutes) }\end{array}$ & $\begin{array}{c}\text { Total } \\
\text { number of } \\
\text { nurses }\end{array}$ & $\begin{array}{l}\text { Total } \\
\text { number } \\
\text { of team } \\
\text { members }\end{array}$ \\
\hline 1 & 2 & Orthopaedics & Fractured clavicle & 75 & 3 & 9 \\
\hline 2 & 3 & Orthopaedics & Total hemiarthroplasty & 65 & 3 & 9 \\
\hline 3 & 2 & Orthopaedics & Total knee replacement & 180 & 3 & 6 \\
\hline 4 & 1 & General surgery & Chest abscess & 95 & 3 & 7 \\
\hline 5 & 2 & Neurosurgery & Excision tumour & 210 & 3 & 7 \\
\hline 6 & LA & Neurosurgery & Ganglionectomy by radiofrequency & 50 & 2 & 8 \\
\hline 7 & 3 & Neurosurgery & Burr holes and insertion of shunt & 155 & 3 & 7 \\
\hline 8 & 1 & Trauma & Removal of glass from foot & 60 & 3 & 7 \\
\hline 9 & 4 & Trauma & Proximal femoral nail & 110 & 3 & 8 \\
\hline 10 & 2 & Orthopaedics & Bilateral knee replacement & 120 & 3 & 8 \\
\hline 11 & 2 & Plastics & Mastectomy and axillary clearance & 165 & 3 & 8 \\
\hline 12 & 3 & Plastics & Mastectomy and axillary clearance & 115 & 3 & 8 \\
\hline 13 & 3 & Plastics & Excision of multiple lesions & 125 & 4 & 8 \\
\hline 14 & LA & Plastics & Excision mucosal biopsy & 30 & 2 & 5 \\
\hline 15 & 3 & General surgery & Staging laparoscopy & 45 & 4 & 8 \\
\hline 16 & 3 & General surgery & Ivor Lewis and thoracotomy & 410 & 2 & 11 \\
\hline 17 & 1 & Plastics & $\begin{array}{l}\text { Mastectomy and DIEP (deep inferior } \\
\text { epigastric perforator artery) flap }\end{array}$ & 410 & 5 & 12 \\
\hline 18 & 2 & General surgery & Laparoscopic cholecystectomy & 75 & 3 & 6 \\
\hline 19 & 3 & General surgery & Vasectomy & 40 & 2 & 10 \\
\hline 20 & 2 & Emergency & Laparoscopy & 90 & 3 & 6 \\
\hline 21 & 1 & Emergency & Laparoscopic appendicectomy & 60 & 3 & 8 \\
\hline 22 & 2 & Emergency & Laparoscopic appendicectomy & 80 & 3 & 9 \\
\hline 23 & 4 & Plastics & Excision of multiple lesions & 50 & 3 & 6 \\
\hline 24 & LA & Plastics & Excision of cheek lesion & 35 & 3 & 4 \\
\hline 25 & LA & Plastics & Excision of multiple lesions & 105 & 2 & 6 \\
\hline 26 & 2 & Orthopaedics & Revision hip replacement & 80 & 3 & 9 \\
\hline 27 & 3 & Trauma & $\begin{array}{l}\text { Open reduction and internal fixation } \\
\text { fractured femur }\end{array}$ & 190 & 3 & 9 \\
\hline 28 & 3 & General surgery & Gastrojejunostomy & 225 & 3 & 14 \\
\hline
\end{tabular}

Note: $L A=$ local anaesthetic. 


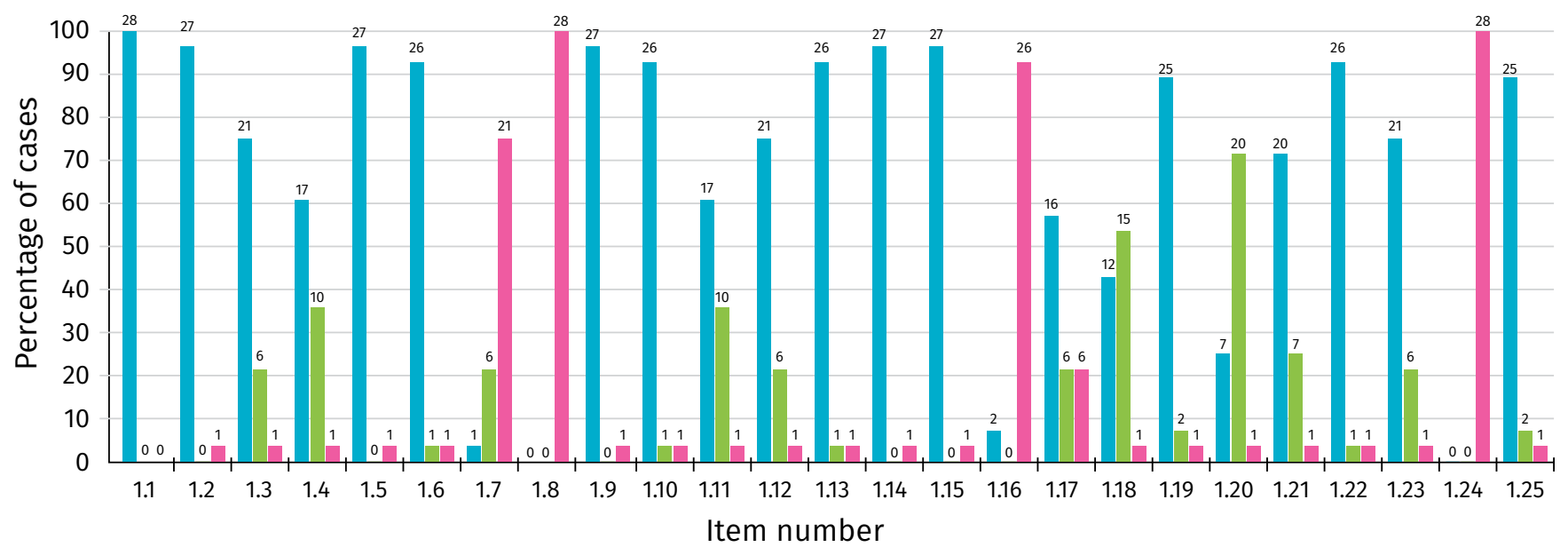

recommended action was observed recommended action was not observed not applicable

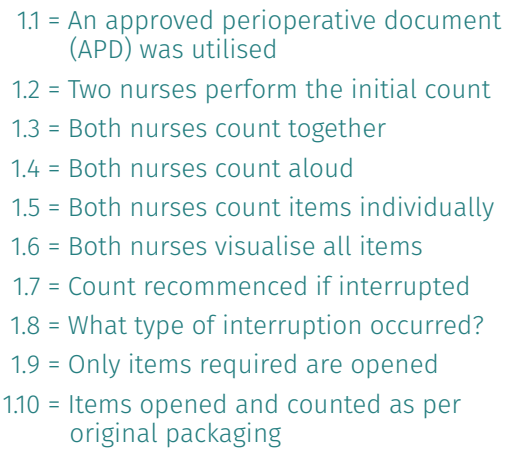

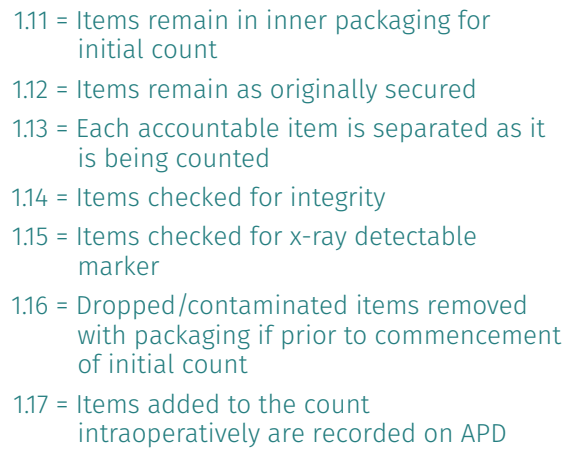

1.11 = Items remain in inner packaging for initial count

1.12 = Items remain as originally secured

$1.13=$ Each accountable item is separated as it is being counted

1.14 = Items checked for integrity

1.15 = Items checked for $\mathrm{x}$-ray detectable marker

$1.16=$ Dropped $/$ contaminated items removed with packaging if prior to commencement of initial count

$1.17=$ Items added to the count intraoperatively are recorded on APD

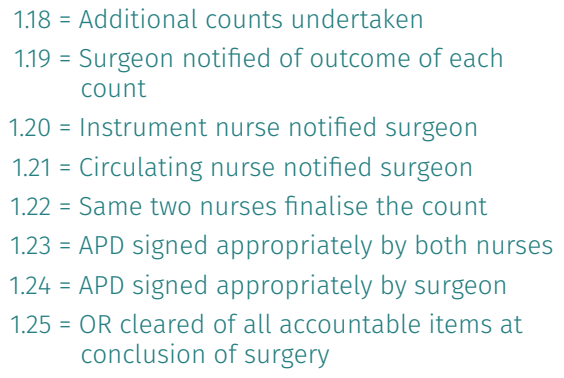

$1.18=$ Additional counts undertaken

$1.19=$ Surgeon notified of outcome of each count

1.20 = Instrument nurse notified surgeon

1.21 = Circulating nurse notified surgeon

1.22 = Same two nurses finalise the count

1.23 = APD signed appropriately by both nurses

1.24 = APD signed appropriately by surgeon

1.25 = OR cleared of all accountable items at conclusion of surgery

Figure 2: Compliance with recommended actions as observed for count process (component 1, behavioural indicators 1.1 to 1.25 )

and no items were deleted except for those that were repetitive. Following the second Delphi review, the tool was deemed ready for piloting.

\section{Pilot study}

\section{Setting and sample}

At the time of the study, the pilot site had 300 beds and eight commissioned operating rooms (ORs), performing over 460 elective surgical cases per month across all specialties. Over 65 staff were employed in the OR facility including registered nurses, clinical nurses and anaesthetic technicians.

\section{Interrater reliability}

The pilot study was conducted over three days and observational data collected by two perioperative nurses - one was a researcher for this study and the other a doctoral student. Twelve nurses were observed undertaking surgical counts for six procedures over 7.7 hours (463 minutes) of surgical time. Surgical time was recorded from when the patient was brought into the OR, asleep or awake, to when they left the OR for the Post Anaesthesia Care Unit (PACU). Each procedure lasted 25 to 150 minutes.

Six procedures were required to achieve the minimum sample size for interrater reliability ${ }^{8}$. Case information relative to specialty, operative time, patient ASA (American Society of Anaesthesiologists risk grading for anaesthesia) and procedure was collected to contextualise observations to better explain the results.

\section{Consistency of observers}

Observations included 744 individual behavioural indicator items observed in relation to the count process for the six surgical procedures. The two raters used the observational tool specifically designed for this study.

\section{Results}

The two raters agreed on the count behaviours that were observed and those not observed for 726 of the 744 observations. Cohen's Kappa reflected a high level of interrater agreement ( $K=0.85, p<.0001)$. Figure 1 illustrates the interrater disagreement across components 1, 4, 11 and 12. All other items reflected a 100\% agreement and are not illustrated in the table. 


\section{Main observational study}

\section{Sample and setting}

The main study site was a large metropolitan public tertiary hospital which at the time of the study had 13 commissioned operating theatres with over 800 surgical procedures being performed per month across elective, urgent and emergent cases. All specialties except obstetrics, neonates and paediatrics were covered. The unit employed all categories of perioperative staff including registered nurses, clinical nurses and staff development nurses.

Observations occurred over two consecutive weeks between 7.00 am and 7.00 pm Monday to Friday. Count processes of nursing staff were observed across six different specialties. Surgical time included from when the patient arrived in the OR, awake or asleep, until they left the OR for the PACU.

\section{Method}

The observational tool was used to collect relevant data in relation to the count process. At the beginning of the tool there was an area to document case information relative to specialty, operative time, patient ASA and procedure. This information was aimed at contextualising the observations to better explain the observations and determine other factors that may have influenced the count process undertaken by the nurse. Information on the number of staff members involved in the case was also collated as this could have an impact on the count process. A field diary recorded notes, including mannerisms, conversations and processes, to explain why items were not observed and what may have hindered nurses' ability to undertake the count process. Structured observations allowed description of count behaviours.

\section{Data analysis}

Absolute ( $n$ ) and relative (\%) values were used to describe frequencies of behavioural indicators observed using the SCOT. Compliance rates for individual behavioural indicators were calculated as a percentage using the formula $100 \mathrm{n} / \mathrm{d}$ where $\mathrm{n}$ is the number of cases in which the recommended behaviour was observed and $d$ is the total number of cases in which the recommended behaviour was required. Compliance rates for each of the 14 components of the SCOT were calculated by using the formula $100 \mathrm{~N} / \mathrm{D}$ where $\mathrm{N}$ is the total number of 'Yes's recorded for each component and $D$ is the number of applicable behavioural indicators that had been observed (i.e. the total number of behavioural indicators observed for a component minus the number of ' $N$ /A's recorded for that component). The overall compliance rate for undertaking a surgical count as recommended by the ACORN accountable items standard was calculated in the same way by dividing the total number of 'Yes's recorded on the SCOT by the number of applicable behavioural indicators that had been observed (i.e. the total number of behavioural indicators observed minus the number of 'N/A's recorded on the SCOT).

\section{Results}

The SCOT was used in 28 procedures over six different specialties. In all, 83 nursing staff including 54 circulating room nurses and 29 instrument nurses were observed by the first author over 57 hours (3450 minutes) surgical time. Table 3 shows the case demographics that provided relevant data to be considered when a count process was not clearly followed. Of the 14 components in the SCOT, eight were seen to occur by the researcher and six were not seen to occur (see Table 4).

\section{Count process}

The first component of the SCOT is count process. Figure 2 shows the 25 behavioural indicators of the count process and the compliance observed for each of them. The following observations are of note:

- the instrument and circulating nurse were observed counting aloud (behavioural indicator 1.3, $n=21 / d=27,78 \%$ compliance) and together during 17 cases (behavioural indicator $1.4, \mathrm{n}=17$ / $d=27,63 \%$ compliance) in the initial count process but in subsequent and final counts only the instrument nurse counted aloud, indicating a lack of consistency in this process

- the count process was interrupted on many occasions. These interruptions occurred because the surgeon requested assistance or additional items from the instrument nurse. Behavioural indicator 1.7 is 'Count recommenced if interrupted'. Field notes indicated that the count process often resumed from the point it had been interrupted, instead of starting again from the items that were being counted at the time.

- the ACORN accountable items standard recommends that all accountable items should remain in their original packaging until they have been accounted for (behavioural indicator 1.11); however, the researcher observed the instrument nurses removing items from their original packaging, e.g. loading scalpel blades onto their respective handles or sutures onto needle holders prior to counting. The recommended behaviour was observed in 17 of the 28 cases $(n=17 / d=27,63 \%$ compliance). 
- the field notes described instances where instrument nurses were not opening suture packets to show the circulating nurse the number of needles in the pack. The practice of removing the paper strip or plastic bag from around swabs that secured them in their original numbers was common (behavioural indicator $1.12, \mathrm{n}=21$ / $d=27,78 \%$ compliance). This practice was performed so the swabs could be folded and placed in a corner on the instrument trolley in preparation for the first count.

- the process to determine how many counts were needed for a given procedure was not clear. Additional counts were undertaken in 12 cases (behavioural indicator 1.18, $n=12 / d=27,44 \%$ compliance). Field notes illustrated instances where the most senior nurse in the room would make the final decision on how many counts would be undertaken, which was rarely challenged by the scrub team.

- there was inconsistency in terms of who should inform the surgeon of the count outcome. Field notes indicated that most often the circulating nurse would notify the surgeon of the outcome of the count (behavioural indicator 1.21, $n=20 / d=27,74 \%$ compliance) but did not always wait for a response before carrying on with their duties. Notably, the surgeon rarely acknowledged the count outcome; however, this was not the case when the instrument nurse notified the surgeon of the count outcome (behavioural indicator $1.20, n=7$ / $d=27,26 \%$ compliance).

Due to the nature of the procedures observed and limited knowledge of surgeons' preferences for particular cases it was difficult for the researcher observing the procedure to determine whether only required accountable items and instruments were opened (behavioural indicator 1.9, $n=27 / d=27,100 \%$ compliance) and that all appropriate packs and instruments had been checked for integrity (behavioural indicator $1.14, n=27 / d=27,100 \%$ compliance) and $x$-ray detectable markers (behavioural indicator $1.15, \mathrm{n}=27 / \mathrm{d}=27$, 100\% compliance).

Another anomaly in the count process was the discarding of accountable items by the circulating nurse into the waste bin immediately following the second count, rather than after the final count. This was explained to the researcher as a 'time saver', and these items were just re-recorded as 'correct' for the third count.

\section{No count required}

'No count required' should only occur when no accountable items are used for the case or there is no surgical incision that would allow accountable items to be retained. Of the 28 cases observed (see Table 3 ), only one was classed as 'no count required' - a ganglionectomy by radiofrequency (case \#6). The patient received a local anaesthetic and no instrument nurse was allocated to the procedure.

\section{Count relief}

The ACORN accountable items standard recommends that relief time be included in the APD (behavioural indicator $6.4, \mathrm{n}=2$ / $\mathrm{d}=11,18 \%$ compliance); this ideally occurs whenever the instrument or circulating nurse is relieved for a break during a procedure (behavioural indicator 6.1, $n=2 / d=14$, $14 \%$ compliance) and also applies when a nurse is being relieved permanently (behavioural indicator $6.5, n=3 / d=14,21 \%$ compliance). This is undertaken so that if there is an issue with the final count staff involved with the procedure may be followed up appropriately.

\section{Sequential and simultaneous procedures}

During this study the researcher observed three sequential or simultaneous procedures. These cases were described in field notes as being somewhat disorganised, with up to three circulating nurses handing up accountable items simultaneously to the scrub nurse.

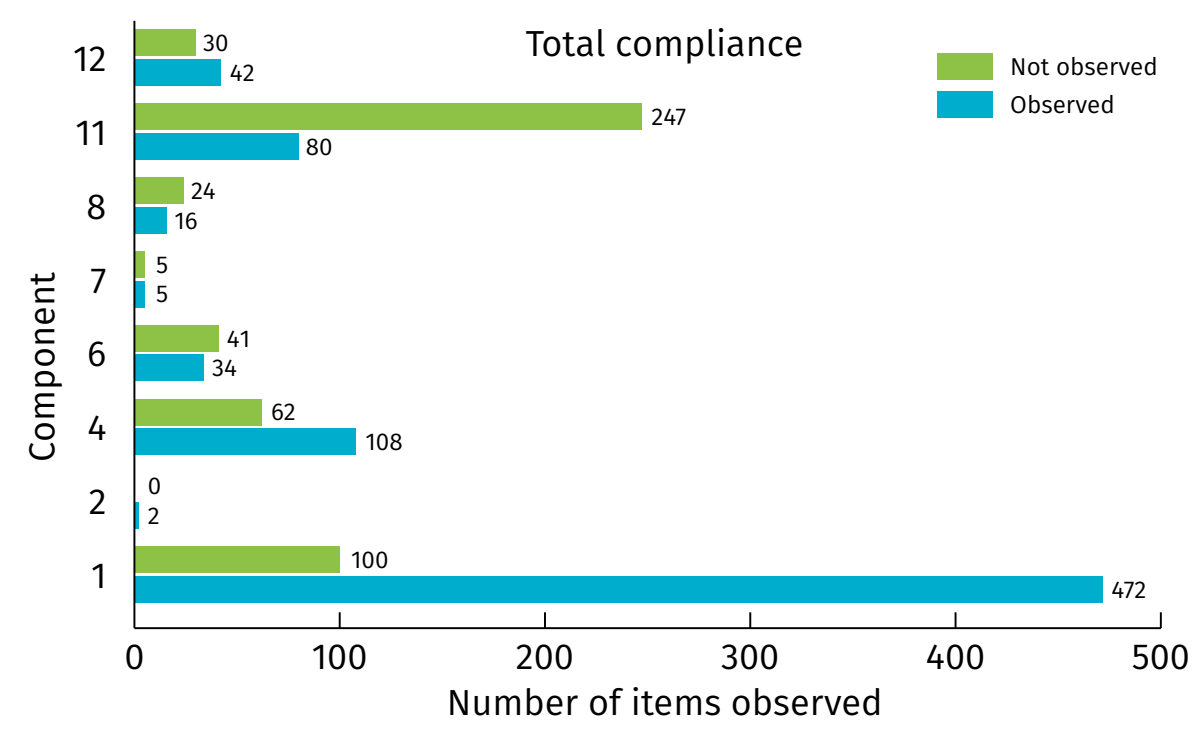

Figure 3: Compliance for components of the observational tool that were observed by the researcher 
An example of the risk of such disorganisation was during one procedure the final count was incorrect and the circulating nurse just added the extra number of items to the count sheet.

\section{Tray lists}

Tray lists were attached to nearly every instrument tray opened by the circulating nurse (behavioural indicator $11.2, n=25 / d=28,89 \%$ compliance). The researcher was not always able to see whether the list had been signed by the sterilisation technician as the document was often discarded into the waste before signatures could be confirmed. Field observations also confirmed that because tray lists were discarded, the columns that had been provided on the tray list to count and check off instrumentation were not being used by the nurses. The instrument and circulating nurses' details, which would assist the sterilisation department in the event of any discrepancies in the trays returned, were also omitted from the tray list documentation. The patient's medical record number and the date of the procedure were also omitted as the tray list was not used in the way recommended by the ACORN accountable items standard.

Occasionally the circulating nurses would place the tray list on the bottom of the instrument trolley, so it could be returned with the tray for reprocessing (behavioural indicator 11.14, ( $n=21 / d=28,75 \%$ compliance). The process for counting instrumentation was somewhat inconsistent, as some nurses counted all instruments while others counted just a few.

\section{Progressive counting away technique}

The researcher observed counting and handing off of swabs from the worktable that did not follow best practice. When items were 'counted off', they were not always opened out fully by either the instrument or circulating nurse (behavioural indicator 12.1, $\mathrm{n}=3$ / $d=28,11 \%$ compliance). Once placed in the count receptacle, they were not recounted and the process of labelling the bagging receptacle with the patient's name or number was not seen to occur. No count discrepancies were observed that involved the reopening of the bagging receptacle.

\section{Observed compliance}

As described, eight of the 14 components of the observational tool were seen by the researcher during the 28 procedures observed. Figure 3 displays the compliance for each of these eight components based on documentation of individual behavioural indicator items observed.

\section{Table 4: Components that did not occur}

\begin{tabular}{|c|l|l|}
$\begin{array}{c}\text { Component } \\
\text { number }\end{array}$ & Component & Notes \\
\hline 3 & $\begin{array}{l}\text { Accountable items } \\
\text { removed from the OR }\end{array}$ & $\begin{array}{l}\text { May occur depending on the } \\
\text { procedure but this was not observed } \\
\text { to occur by the researcher }\end{array}$ \\
\hline 5 & $\begin{array}{l}\text { Incorrect number of } \\
\text { items in a package }\end{array}$ & $\begin{array}{l}\text { Considered a rare occurrence in the } \\
\text { OR and was not observed to occur by } \\
\text { the researcher }\end{array}$ \\
\hline 9 & $\begin{array}{l}\text { Intentionally retained } \\
\text { items }\end{array}$ & $\begin{array}{l}\text { Considered a rare occurrence in the } \\
\text { OR and was not observed to occur by } \\
\text { the researcher }\end{array}$ \\
\hline 10 & $\begin{array}{l}\text { Removal of } \\
\text { intentionally retained } \\
\text { items }\end{array}$ & $\begin{array}{l}\text { Considered a rare occurrence in the } \\
\text { OR and was not observed to occur by } \\
\text { the researcher }\end{array}$ \\
\hline 13 & Emergency situation & $\begin{array}{l}\text { Although the researcher observed } \\
\text { cases considered emergencies, } \\
\text { there was always enough time to } \\
\text { undertake a count }\end{array}$ \\
\hline \multirow{2}{*}{$\begin{array}{l}\text { Incorrect count } \\
\text { Considered a rare occurrence in the } \\
\text { OR and was not observed to occur by } \\
\text { the researcher }\end{array}$} \\
\hline
\end{tabular}

Table 4 provides a list of the six components that were not seen to occur by the researcher during the observational period.

The overall compliance rate for undertaking a surgical count as recommended by the ACORN Standards was 60 per cent. Overall there were 1268 behavioural indicator items observed: 759 complied with the ACORN Standard's recommendations for undertaking a surgical count and 509 did not comply. The overall compliance rate was calculated by dividing the total number of compliant behavioural indicator items (759) by the total number of items that had been observed minus the not applicable items (1268), then multiplying by 100 to get a percentage.

Overall compliance rate:

$$
\frac{759}{1268} \times 100=(59.85) 60 \%
$$

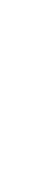


The overall non-compliance rate was 40 per cent, calculated in the same way.

Overall non-compliance rate:

$$
\frac{509}{1268} \times 100=(40.14) 40 \%
$$

\section{Discussion}

Structured observations of perioperative nurses' practices while undertaking a surgical count provided a snapshot of the challenges that perioperative nurses encountered during the count process. Observations indicated a lower-than-expected rate of compliance and conformity. The main barriers were found to be time pressures, the pace of the surgical environment and expectations of surgeons and co-workers; enablers were personal factors including the nurse's knowledge, experience and familiarity with standardised expectations.

Our observations suggest that perioperative nurses were often placed under pressure to complete a surgical count either by the surgery finishing more quickly than anticipated, surgeon behaviour or the anaesthetic team pushing drapes away to wake the patient up before a final count had been completed, which was also found in a study by Butler et al. ${ }^{9}$. These pressures lead to the count process not always being undertaken correctly and therefore are a hindrance to undertaking best practice. Time pressure and the ability to turn procedures around quickly, which relates to productivity, was also described in the literature as contributing to more than half of incorrect counts ${ }^{10}$.

The importance of perioperative nurses' knowledge about the count process was another key finding in this research. Knowledge enabled perioperative nurses and provided the confidence they required to question and challenge practices. However, colleagues' behaviour and hierarchy within the operating room sometimes prevented nurses from challenging others' practices, especially for the more junior nurses who may have found it easier to do as somebody else wanted rather than follow the correct process. This finding was consistent with studies by Cima et al.11, Freitas et al.12 and Norton et al.13.

The process of undertaking a surgical count differed between perioperative nurse and surgical specialty. This study found inconsistencies in the count process as not all perioperative nurses followed best practice as recommended by the ACORN accountable items standard, with 40 per cent of those observed deviating from best practice principles. Much of the literature related to surgical counting describes standardised processes and the ability to follow those processes to improve the chances of a correct count at the conclusion of a

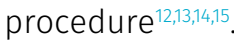

The development of an observational tool that aligned with the process recommended by the ACORN accountable items standard and was expertly reviewed and refined by perioperative peers added strength to the study. The tool produced a definitive document that provided a clear delineation of the steps that the perioperative nurse needs to follow when undertaking a surgical count. Use of this tool should enable nurses to ensure positive outcomes for the surgical patient by ensuring no items were left unintentionally within the surgical cavity.

The opportunity to observe these practices in real time assisted in providing an objective and measurable process around challenges in undertaking the surgical count process. The field diary relating to each observed case provided reflections on the actions occurring in the OR. These diary entries, together with the data recorded on the observational tool, provided an in-depth understanding of the contextual barriers and enablers teams faced while trying to undertake a surgical count process according to the ACORN accountable items standard ${ }^{1}$ For example, the surgeon interrupting the count process to request an instrument or the circulating nurse leaving the OR to gather further equipment or items.

\section{Implications for perioperative nursing}

Perioperative nurses face many challenges in the OR that may affect their ability to follow best practice in relation to the surgical count. This research provides empirical data relative to these daily challenges. Ongoing research is needed into policy development, with a focus on implementation strategies that enable perioperative nurses to undertake the surgical count process.

\section{Policy development}

The possibility of retained items by not having an established process for counting was found in a study by Cima et al.16. Perioperative staff involved in surgical counts require consistency and structure to ensure the count process is followed as recommended in the ACORN accountable items standard. HCFs need to co-develop implementation resources, with specialty nurses, surgeons and anaesthetists, that provide guidance around the count process in relation to specific surgical procedures ${ }^{12}$.

Research by Kieft et al.7 found that nurses who were involved in local policy review gained a deeper understanding of the process and 
were better able to follow the guidelines. Norton et al. ${ }^{13}$ undertook a quality-improvement activity that included reviewing and revising their current count policy, and this reduced the number of count discrepancies that they were having. The findings of this study align with the literature, demonstrating the importance of policy development in relation to the surgical count process.

\section{Clinical practice development}

Perioperative nurses need to count aloud and together for all surgical counts so that the surgical team is alerted to what is occurring and know that they should not interrupt. They need to find a clear avenue that ensures minimal disruption from the surgical or nursing team when they are undertaking any components of the count process. Distraction while counting can lead to error or incorrect documentation of items counted. Much of the literature discussing URIs cites many types of distractions in a complex environment as a cause of incorrect counts ${ }^{9,10,18}$. This demonstrates the importance of the count process and the concentration required.

Maintaining items in their original packaging needs to be recommended in the HCF count process. It was observed that instrument nurses would like to remove items to neatly fold them and have sutures loaded ready for the case to start. According to the ACORN accountable items standard it is important that swabs and sutures remain in their original packaging until counted in case there are any discrepancies with the item being counted. Throughout the literature there was no evidence of how this process affects the accuracy of the surgical count; however, the recommendation in the ACORN accountable items standard ${ }^{1}$ provides a systematic method of managing a discrepancy in the original count.

Having multiple nurses handing up items to the instrument nurse may appear to save time but can lead to error in documentation and incorrect counts. Removing possible causative factors that can lead to a count error may, in fact, speed up the count process. Once again, the literature does not provide any evidence to support this principle; however, if the process ensures that documentation is completed correctly then there is a possibility of reducing a potential risk.

Surgical tray lists are an ongoing grey area in the ACORN accountable items standard. A lack of standard processes for the tray list can put pressure on the HCF to develop a process that is efficient and reduces the possible impact of an incorrect count. HCFs need to find a way to include tray lists into the count process and provide a safer environment to prevent retained items in surgery. The process of using tray lists and their impact on the surgical count is not described within the literature. As documented by $\mathrm{Edel}^{14}$, reducing variation in practices can reduce the risk of count errors. Some specialties use a large number of surgical trays which may impact the nurse's ability to count each piece of paper included in the set, moving away from the process recommended in the ACORN accountable items standard.

\section{Limitations}

A limitation to this observational study was the use of a single hospital locale. Perioperative nurses working in this hospital may undertake practices differently to the general perioperative nursing population. The researcher recruited nurses from different specialties and with different levels of experience.
As with all observational studies, we were mindful of the possibility of a Hawthorne effect - that subjects being observed will change their practice or behaviour while being watched $^{19}$. The first author (VW) spent a prolonged period at the research site so potential participants were able to engage and ask questions. During field observations, participants were aware of the researcher being present but as soon as procedures began participants tended to revert to normal daily activities $^{20}$.

\section{Conclusion}

This observational study has described the count behaviours of perioperative nurses using a rigorously developed observation tool. The study has made a major contribution to the literature on quality and safety in perioperative nursing by developing a validated tool that can be used in other locations to conduct surgical audits of count procedures.

The analysis provides evidence of the challenges faced by perioperative nurses while undertaking the surgical count but further discussion is required to gain an understanding of the challenges and why perioperative nurses did not question or speak up when there was a breach in the recommended count process.

This study demonstrates the need for HCFs to develop a policy and procedure for undertaking surgical counts, taking into consideration the complexity and clinical requirements of certain procedures and specialties. Perioperative nurses may be more inclined to follow policy and procedure around the surgical count if they feel it is relevant and required for the surgical procedure they are undertaking. 


\section{References}

1. Australian College of Perioperative Nurses (ACORN). Standards for perioperative nursing in Australia $14^{\text {th }}$ ed. Adelaide, SA: ACORN; 2016.

2. Australian Commission on Safety and Quality in Health Care (ACSQHC). Australian sentinel events list [Internet]. Sydney: ACSQHC; 2018[cited 2021 April 26]. Available from: www.safetyandquality.gov.au/ourwork/indicators/australian-sentinel-eventslist/.

3. Patient Safety Surveillance Unit. Your safety in our hands in hospital: An integrated approach to patient safety surveillance in WA hospitals, health services and the community: 2016 [Internet] Perth: Western Australian Department of Health; 2016 [cited 2021 April 26]. Available from: ww2.health.wa.gov.au/ /media/Files/ Corporate/Reports\%20and\%20publications/ Patient\%20Safety/Your_Safety_In_Our_ Hands_Report_2016.pdf.

4. The Joint Commission. Sentinel Event Alert 51: Preventing unintended retained foreign objects [Internet]. Chicago: The Joint Commission; 2013 [cited 2021 April 26]. Available from: www.jointcommission.org/ sea_issue_51/.

5. Rowlands A, Steeves R. Incorrect surgical counts: A qualitative analysis. AORN J 2010;92(4):410-419. DOI:10.1016/j. aorn.2010.01.019.
6. Australian College of Perioperative Nurses (ACORN). Standards for perioperative nursing in Australia $16^{\text {th }}$ ed. Adelaide, SA: ACORN; 2020.

7. Larsson H, Tegern M, Monnier A, Skoglund J, Helander, C, Persson, E et al. Content validity index and intra- and inter-rater reliability of a new muscle strength/endurance test battery for Swedish soldiers. Plos One 2015;10(7). e0132185.

8. Walter SD, Eliasziw M, Donner A. Sample size and optimal designs for reliability studies. Stat Med 1998;17(1):101-110. DOI:10.1002/ (SICI)1097-0258(19980115)17:1<101::AIDSIM727>3.0.CO;2-E.

9. Butler M, Ford R, Boxer E, Sutherland-Fraser S. Lessons from the field: An examination of count errors in the operating theatre. ACORN J 2010;23(3):6.

10. Steelman V, Cullen J. Designing a safer process to prevent retained surgical sponges: A healthcare failure mode and effect analysis. AORN J 2011;94(2):132-141.

11. Cima RR, Kollengode A, Storsveen AS, Weisbrod CA, Deschamps C, Koch MB et al. A multidisciplinary team approach to retained foreign objects. Jt Comm J Qual Patient Saf 2009;35(3):123-132.

12. Freitas P, Silveira R, Clark A, Galvão C. Surgical count process for prevention of retained surgical items: An integrative review. J Clin Nurs 2016;25(13-14):1835-1847.

13. Norton EK, Martin C, Micheli AJ. Patients count on it: An initiative to reduce incorrect counts and prevent retained surgical items. AORN J 2012;95(1):109-121. DOI:10.1016/j. aorn.2011.06.007.
14. Edel EM. Surgical count practice variability and the potential for retained surgical items. AORN J 2012;95(2):228-238. DOI:10.1016/j. aorn.2011.02.014.

15. McDonald R, Waring J, Harrison S, Walshe K, Boaden R. Rules and guidelines in clinical practice: A qualitative study in operating theatres of doctors' and nurses' views. Qual Saf Health Care 2005;14(4):290-294. DOI:10.1136/qshc.2005.013912.

16. Cima RR, Kollengode A, Garnatz J, Storsveen A, Weisbrod C, Deschamps C. Incidence and characteristics of potential and actual retained foreign object events in surgical patients. J Am Coll Surg 2008;207(1):80-87.

17. Kieft RAMM, Brouwer BJM, Francke AL, Delnoij D. How nurses and their work environment affect patient experiences of the quality of care: A qualitative study. BMC Health Serv Res 2014;14(1):249. DOI:10.1186/1472-6963-14-249.

18. Hariharan D, Lobo DN. Retained surgical sponges, needles and instruments. Ann R Coll Surg Engl 2013;95(2): 87-92. DOI:10.1308/ $003588413 \times 13511609957218$.

19. McCarney R, Warner J, Iliffe S, van Haselen R, Griffin M, Fisher, P. The Hawthorne effect: A randomised, controlled trial. BMC Med Res Methodol 2007;7(1):30. DOI:10.1186/14712288-7-30.

20. Gillespie B, Harbeck E, Lavin J, Hamilton K, Gardiner T, Withers T et al. Evaluation of a patient safety programme on Surgical Safety Checklist compliance: A prospective longitudinal study. BMJ Open Qual 2018;7(3). E000362. DOI:10.1136/bmjoq-2018-000362. 